\title{
Impactos gerados pela fiscalização do excesso de peso em veículos comerciais na rodovia BR-153 em Gurupi - TO
}

\author{
Impacts generated by the inspection of excess weight in commercial vehicles on the BR-153 \\ highway in Gurupi - TO
}

Impactos generados por la inspección de exceso de peso en vehículos comerciales en la carretera

BR-153 en Gurupi - TO

Recebido: 11/05/2021 | Revisado: 17/05/2021 | Aceito: 20/05/2021 | Publicado: 24/05/2021

\author{
Samara Pereira da Costa \\ ORCID: https://orcid.org/0000-0003-4485-8909 \\ Universidade de Gurupi, Brasil \\ E-mail: Samara_marli@hotmail.com \\ Emanoel Gomes dos Santos Aguiar \\ ORCID: https://orcid.org/0000-0003-2181-1614 \\ Universidade de Gurupi, Brasil \\ E-mail: emanoelgsantos1618@gmail.com \\ Luara de Carvalho Silva Gama \\ ORCID: https://orcid.org/0000-0003-4289-6418 \\ Universidade de Gurupi, Brasil \\ E-mail: engluara8@gmail.com \\ Luiz Felipe da Silva da Fonseca \\ ORCID: https://orcid.org/0000-0001-8649-6702 \\ Universidade de Gurupi, Brasil \\ E-mail: elffonseca_rj@hotmail.com
}

\begin{abstract}
Resumo
Neste artigo são abordados os impactos gerados pela fiscalização do excesso de peso em veículos comerciais na rodovia BR153 no município de Gurupi/TO. Apresenta-se a grande dependência da indústria com o transporte rodoviário, as inconsis-tências do sistema de fiscalização nacional, a necessidade de coleta de dados de tráfego para a tomada de decisões, o dimen-sionamento de um pavimento novo ou reforço levando em consideração o número "N" que representa o parâmetro da solici-tação do tráfego ao pavimento. No estudo, conclui-se que o excesso de peso em veículos comerciais é um dos principais fato-res da destruição das rodovias brasileiras e da diminuição considerável da vida útil. E, por fim, evidenciou-se os impactos da fiscalização do excesso de peso, como a redução da degradação do pavimento e a prevenção de acidentes causados pelo tráfego de caminhões com excesso de peso.
\end{abstract}

Palavras-chave: Tráfego; Excesso de peso; Fiscalização de peso; Patologias no pavimento; Pavimentação.

\begin{abstract}
In this article, the impacts generated by the inspection of excess weight in commercial vehicles on the BR153 highway in the municipality of Gurupi / TO are addressed. There is a great dependence of the industry on road transport, the inconsistencies of the national inspection system, the need to collect traffic data for decision making, the dimensioning of a new pavement or reinforcement taking into account the number " $\mathrm{N}$ " That represents the parameter of the traffic request to the pavement. In the study, it is concluded that excess weight in commercial vehicles is one of the main factors in the destruction of Brazilian highways and in the considerable decrease in useful life. And, finally, the impacts of the inspection of excess weight were evidenced, such as the reduction of the degradation of the pavement and the prevention of accidents caused by the traffic of overweight trucks.
\end{abstract}

Keywords: Traffic; Overweight; Weight inspection; Pathologies on the pavement; Paving.

\section{Resumen}

En este artículo se abordan los impactos generados por la inspección de exceso de peso en vehículos comerciales en la carretera BR153 en el municipio de Gurupi / TO. Existe una gran dependencia de la industria del transporte por carretera, las inconsistencias del sistema nacional de inspección, la necesidad de recolectar datos de tránsito para la toma de decisiones, el dimensionamiento de un nuevo pavimento o refuerzo tomando en cuenta el número "N" que representa el parámetro de la solicitud de tráfico al pavimento. En el estudio, se concluye que el exceso de peso en vehículos comerciales es uno de los principales factores en la destrucción de las carreteras brasileñas y en la considerable disminución de la vida útil. Y, finalmente, se evidenciaron los impactos de la inspección de exceso de peso, como la 
reducción de la degradación del pavimento y la prevención de accidentes provocados por el tráfico de camiones con sobrepeso.

Palabras clave: Tráfico; Sobrepeso; Inspección de peso; Patologias en el pavimento; Pavimentación.

\section{Introdução}

O Brasil possui uma demanda muito elevada no que diz respeito ao transporte de mercadorias. Segundo Réus, Júnior e Fontenele (2016), aproximadamente $60 \%$ desta demanda é suprida pelo transporte rodoviário, já que as rodovias estão presentes em todo território, facilitando assim o escoamento e tornando a economia dependente deste sistema.

De acordo com o DNIT (2021), as rodovias do território nacional possuem extensões de 241.242,8 km atuais, com $151.710,7 \mathrm{~km}$ totais pavimentadas. Onde:

- $\quad 120.819,1 \mathrm{~km}$ do Sistema Nacional de Viação (SNV), onde 64.177,1 km são pavimentadas (53,11\% da rede);

- $\quad 79.721,2 \mathrm{~km}$ de jurisdição federal, onde $52.005,0 \mathrm{~km}$ são pavimentadas (65,24\% da rede);

- $\quad 28.883,7 \mathrm{~km}$ estaduais, com $23.709,8 \mathrm{~km}$ pavimentados ( $82,08 \%$ da rede);

- $\quad 9.692,3 \mathrm{~km}$ de concessão federal, onde $100 \%$ são pavimentadas;

- $\quad 2.126,5 \mathrm{~km}$ de convênios de delegação, com 2.107,0 km pavimentados (99,08\% da rede).

A fiscalização do excesso de peso dos veículos comerciais de carga nas rodovias de forma efetiva e contínua é uma deficiência no sistema de tráfego do país.

Um dos motivos para o mau estado que se encontram as rodovias brasileiras é o excesso de peso dos veículos comerciais de carga. Este efeito destrutivo do excesso de peso pode ser percebido no dimensionamento dos pavimentos por meio do Fator de Equivalência de Carga (FEC), que relaciona cada tipo de eixo ou conjunto de eixos ao eixo padrão, e é utilizado na determinação do número equivalente de operaç̃os do eixo padrão (N), que representa todo o tráfego de forma simplificada. Os pavimentos são dimensionados para os limites de peso estabelecidos em lei, portanto o excesso de peso além desses limites danifica o pavimento que foi dimensionado para resistir os esforços no limite do peso estipulado em lei (Réus; Júnior; Fontenele, 2016, p.51).

O objetivo desse artigo é verificar os efeitos da fiscalização do excesso de peso em veículos comerciais de carga, apresentando os dados mensais coletados e os impactos gerados no tráfego na rodovia BR-153 no munícipio de Gurupi.

\section{Fundamentação Teórica}

\subsection{Tráfego}

Segundo DNIT (2006), no estudo de tráfego, a contagem de tráfego e as pesquisas de campo (ocupação de cargas), sobre a região de interesse, junto as estes são adquiridos dados como tempo de viagem, pesagem de veículos, origem/destino e classificação direcional.

As pesquisas volumétricas são feitas num período de sete dias, por vinte e quatro horas diárias por posto de contagem, sendo utilizados contadores automáticos ou manuais. As contagens direcionais também são necessárias para se obter todos os fluxos de tráfego nas interseções. A pesquisa de ocupação de carga é feita no campo durante quatro dias, no horário comercial, tendo o objetivo de descobrir o destino e a carga de cada veículo, sua capacidade e o volume de mercadoria carregado para que seja definido como o tráfego flui na região de estudo (Fonseca, 2013).

Após a coleta dos dados, é feito o processamento para determinar o fluxograma de tráfego e elaborar o projeto de interseção. As taxas de crescimento do volume de tráfego poderão ser baseadas em séries históricas existentes ou levantamento de dados socioeconômicos regionais. A evolução da população e da renda per capita, por exemplo, tem grande influência no crescimento da frota de automóveis, enquanto a produção industrial e agropecuária e venda de combustíveis podem ser associados ao crescimento da frota (BRASIL, 2006 apud Schmit, 2015, p.28). 
Conforme Soares e Motta (2001, apud Fonseca,2013, p.10), o tráfego de uma rodovia é um fator importante e pode ser observado no dimensionamento de um pavimento rígido ou flexível, seja por método empírico ou mecanístico, pois este representa a principal solicitação a qual está sujeita o pavimento.

Atualmente, é necessário padronizar o tráfego, pois tem formas complexas, como: diferentes cargas, vários tipos de veículos, velocidades, eixos e rodas. Por isso, é importante apresentar o tráfego total e a intensidade das cargas pelo número "N". O número "N" é o parâmetro no dimensionamento de pavimentos que representa o tráfego total e a intensidade que as cargas vão atuar, sendo o número equivalente de operações do eixo padrão de 8,2t e expressa um tráfego virtual que produz um mesmo efeito destrutivo do tráfego real (Silva et al.,2011).

Segundo Soares e Motta (2001, apud Fonseca,2013, p.11), a forma mais simples de se converter o tráfego em número "N" não seria a vida útil dos pavimentos, mas a sua forma de ruptura. $\mathrm{O}$ dimensionamento mais adequado e bastante usado no Brasil no pavimento é o de concreto de cimento Portland, pois considera o efeito individual dos eixos que vão solicitar o pavimento, melhorando assim a estrutura.

É através do estudo de tráfego que podemos entender vários fatores relacionados à rodovia, tais como: total de veículos, excesso de peso e o impacto gerado por CMT (capacidade máxima de tração) pelo excesso de peso por eixo ou pelo PBT (peso bruto total).

Quanto maior o tráfego, maior a solicitação do pavimento, e, consequentemente, mais resistente deve ser. Esse pavimento é dimensionado considerando os limites de peso estabelecidos pela lei, ou seja, em caso de excesso de peso nos veículos, a vida útil das rodovias será afetada, além dos possíveis danos ao sistema mecânico dos veículos podendo provocar acidentes.

\subsection{Dimensionamento de pavimento novo ou reforço no pavimento}

O dimensionamento da estrutura de um pavimento tem como objetivo o cálculo de espessuras e a escolha de materiais de forma que a vida útil do mesmo corresponda a certo número de solicitações de carga do projeto, tendo em conta determinados estados limites de utilização, de forma econômica. Assim, além da avaliação da estrutura é necessário ainda realizar uma análise de custo-benefício da estrutura projetada (BRASIL, 2006).

De acordo com Fonseca (2020), os parâmetros de Tráfego obtidos para dimensionar um pavimento novo ou reforço no pavimento existente, são alcançados a partir do estudo das cargas rodoviárias. O pavimento é dimensionado em função das características dos materiais que o compõem e das cargas que o solicita.

O estudo das cargas rodoviárias se calça através do estudo de tráfego, sendo a partir deste que se obtém dados como a classificação de uma rodovia, o nível de serviço, a determinação do fluxo de tráfego, o estudo de implantação de vias e outros. O estudo de tráfego é muito amplo, logo busca-se focar especificamente no estudo das cargas rodoviárias, pois é a parte que interessa para o dimensionamento do pavimento (Fonseca, 2020).

O estudo de tráfego tem por objetivo realizar uma verificação de viabilidade da elaboração de projetos de engenharia rodoviária voltados para a construção de novas rodovias ou a melhoria de vias já existentes. O parâmetro que corresponde ao tráfego no dimensionamento de um pavimento é o número "N". O estudo de tráfego possui uma grande importância para o dimensionamento do pavimento e para a determinação da capacidade da via, através do parâmetro VMD (volume médio diário de veículos) (BRASIL, 2006).

Com a determinação dos parâmetros de tráfego pode-se fazer o dimensionamento da via, utilizando o prazo de horizonte de projeto e da taxa de crescimento anual adquirida através dos dados socioeconômicos e da série histórica de contagens. No dimensionamento de pavimentos flexíveis, a vida útil ou de projeto geralmente é de 10 anos, podendo variar de acordo com o interesse do órgão responsável pela via. (DNIT, 2006). 
De acordo com Fonseca (2013), através das pesquisas de pesagem, é determinado o peso por eixo ou conjunto de eixos dos vários tipos de veículos que utilizam o trecho. Uma via em que o fator de veículo for elevado, significa dizer ser elevada a porcentagem de veículos com grande quantidade de carga incide sobre a mesma, como caminhões de carga. O valor do volume médio diário de tráfego não leva em consideração se o trânsito possui mais ou menos caminhões e se está carregado ou não, pois somente classifica a quantidade de veículos trafegando em função de cada tipo ou quantidade de eixos, traduzindo a composição da frota, sem levar em consideração a carga contida em cada veículo pois somente classifica a quantidade de veículos trafegando em função de cada tipo ou quantidade de eixos, traduzindo a composição da frota, sem levar em consideração a carga contida em cada veículo.

Segundo Fonseca (2020), para o dimensionamento do pavimento, veículos como carros e motocicletas são excluídos do cálculo, pois o fator de carga destes é muito baixo e insignificante para gerar dano ao pavimento, assim são contabilizados somente veículos comerciais, ou seja, caminhões e ônibus, classificados, portanto como VMD (Volume médio diário comercial).

Conforme Schmitt (2015), o cálculo do tráfego para o dimensionamento de pavimentos flexíveis é feito de acordo com o número "N", representado pela repetição de eixos equivalente ao eixo padrão de 8,2 tf (ESP 8,2 tf ou de 80 kN). O “N" é o eixo de referência padrão multiplicado pelo número de repetições onde todos os eixos existentes são convertidos no padrão. Este cálculo é feito para toda a vida útil do pavimento estimando qual será o tráfego passante do começo ao fim do projeto.

Normalmente o fator climático regional adotado é igual a 1 e o fator direcional igual a 0,5 (valor utilizado em geral pelo DNIT) para rodovias de pista simples (DNIT, 2006). O número N é calculado através da equação apresentada:

\section{$\mathrm{N}=365 * \mathrm{VMDAc} * \mathrm{D} * \mathrm{FV}$}

Onde:
$\mathrm{N}$ = número de repetições de um eixo padrão simples;
365 = quantidade de dias do ano;
VMDAc = volume médio diário de veículos comerciais acumulado até o ano considerado;
$\mathrm{D}=$ fator de distribuição direcional predominante $(\mathrm{D}=0,25$ a 0,50$)$;
$\mathrm{FV}$ = fator de veículos médio para a frota considerada;

\subsection{Excesso de peso}

Segundo Borges (2012), o excesso de peso em veículos comerciais é um dos principais fatores da destruição das rodovias brasileiras, onde a vida útil de algumas vias chega a ser reduzida consideravelmente. Este problema deve-se também à fiscalização deficiente e multas brandas. Segundo o CTB (Código de Trânsito Brasileiro), em suas disposições preliminares, o trânsito, em condições seguras, é um direito de todos e dever dos órgãos e entidades componentes do Sistema Nacional de Trânsito. Estes cabem, no âmbito das respectivas competências, adotar as medidas destinadas a assegurar esse direito (CTB, 1997).

Vários são os fatores que provocam impactos nas rodovias, dentre eles destacamos o tráfego de veículos com excesso de peso. Este problema é frequente nas rodovias, devido ao desrespeito dos limites estabelecidos pela maioria dos condutores (Albano, 2005).

Conforme Albano (2005), existem poucas atividades de fiscalização em relação à pesagem nas rodovias, são observados alguns fatores existentes além de contribuir para a diminuição da vida útil do pavimento e temos os riscos de acidentes, comprometimento da segurança nas rodovias, a estrutura perde seu conforto, entende-se que todo o excesso de cargas traz efeitos negativos nas rodovias. 


\subsection{Os benefícios da fiscalização do excesso de peso}

Como benefícios oriundos da fiscalização do tráfego com excesso de peso nas rodovias podemos citar a redução da degradação do pavimento, a prevenção de acidentes causados pelo mau funcionamento dos veículos devido ao excesso de peso e o aumento da vida útil do pavimento. As vantagens do uso correto das rodovias também vêm para os condutores dos veículos comerciais, como a melhoria das condições da via, a redução de perdas na movimentação da mercadoria, o encurtamento do tempo de viagem e até mesmo a economia dos custos operacionais dos veículos (Albano, 2005).

Segundo o DNIT (2006), os acidentes envolvendo caminhões provocam a grande maioria das fatalidades todos os anos. O motivo é o fato de os veículos possuírem um peso próprio elevado, sendo agravado pelo excesso de peso fora dos limites. O excesso de peso torna os veículos instáveis e aumenta o risco de tombamento, principal causa de acidentes com caminhões. Também aumenta o tempo de frenagem e provoca sobrecarga nos freios, podendo causar o seu colapso. Isso põe em risco o próprio motorista do caminhão e todos os demais públicos das rodovias, como condutores e passageiros de veículos leves, motociclistas e pedestres.

Certamente, os ganhos decorrentes da redução dos custos de manutenção nas vias com adequada fiscalização dos limites de peso, notadamente do peso por eixo, permitiriam ampliar programas que visassem a ampliação e a melhoria da infraestrutura de transportes do país, ou mesmo poderiam ser revestidos em benefícios para os transportadores de cargas, os quais sentir-se-iam incentivados a respeitar os limites legais estabelecidos (Borges, 2012).

2.5 Legislação aplicada a fiscalização de tráfego com excesso de peso

No Brasil, é comum encontramos caminhões que visivelmente trafegam com excesso de carga o que provoca dificuldade na condução, em especial em curvas e nas frenagens. Também é possível ver caminhões tentando evitar as balanças de fiscalização de excesso de peso. Os procedimentos adotados àqueles pegos trafegando com excesso de peso de mercadoria é o acionamento de outro caminhão para transferir a carga excedente ou, caso não haja essa possibilidade, autorizar o retorno ao local de origem da carga com a aplicação de multa (Nunes, 2008).

Conforme o artigo $9^{\circ}$ da resolução CONTRAN (Conselho Nacional de Trânsito), independentemente da natureza da carga, o veículo poderá prosseguir viagem sem remanejamento ou transbordo, desde que os excessos aferidos em cada eixo ou conjunto de eixos sejam simultaneamente inferiores a $12,5 \%$ (doze e meio por cento) do menor valor entre os pesos e capacidades máximos estabelecidos pelo CONTRAN e os pesos e capacidades indicados pelo fabricante ou importador (Contran, 2015).

A lei 7.408/85 do Brasil, CONTRAN elabora resoluções que permite a tolerância de 5\% (cinco por cento) na pesagem de carga em veículos de transporte e $10 \%$ (dez por cento) sobre os limites de peso bruto transmitido por eixo de veículos à superfície das vias públicas. A resolução no 104 de 21/12/99 alterou tolerância para o excesso de peso por eixo de 5\% para 7,5\%. As resoluções 210 e 211 do CONTRAN, estabelece os limites de peso e dimensões para veículos que transitem por vias terrestres e dá outras providências, e fornece os requisitos necessários à circulação de combinações de veículos de carga.

A Resolução CONTRAN 526/15 referenda a Deliberação no 142 de 17 de abril de 2015 que dispõe sobre a alteração da Resolução CONTRAN no 211, de 13/11/06, e da Resolução CONTRAN no 258, de 30/11/07 e revoga a Resolução CONTRAN no 489 de 05/06/14. A resolução CONTRAN Nº 803, de 22/10/20 consolida as normas sobre infrações de trânsito previstas nos incisos V e X do art. 231 do Código Trânsito Brasileiro (CTB), relativas ao trânsito de veículos com excesso de peso ou excedendo a capacidade máxima de tração.

A chamada Lei da Balança é que se faz cumprir nas rodovias do todo o território nacional, ela estabelece limites de pesos e dimensões dos veículos de carga e de passageiros, essa lei é basicamente a junção de decretos, resoluções e lei do CTB - código de trânsito brasileiro (Contran, 2006). Os postos de pesagem existem para que haja a fiscalização e consequentemente 
inibir o tráfego de veículos com excesso de carga ou pessoas, através de multas e restrições, e também para incentivar a aqueles que cumprem a lei.

De acordo com Albano (2005), apesar de todas as leis e resoluções que regem sobre o transporte de mercadorias e pessoas em rodovias, no Brasil a falta de fiscalização, informação, investimento, pessoal e infraestrutura é o principal causador dos problemas nos pavimentos. Uma reformulação na gestão rodoviária do país é necessária para que a classificação das rodovias melhore e traga a os benefícios esperados.

\section{Metodologia}

A metodologia adotada neste trabalho a princípio foi contextualizar a pesquisa e posteriormente apresentar-se o objetivo. Conseguinte a isto, realizar um estudo em artigos, dissertações de mestrado, resoluções, teses, trabalhos de conclusão de curso, legislação e outros, para se ter uma base para produzir uma fundamentação teórica consistente.

O enfoque do trabalho foi demonstrar os dados de pesagem obtidos a partir de uma operação diária de pesagem da UMO-E-TO-20, estando localizada na Rodovia BR-153/TO, sentido Sul - Norte, próximo ao km 666 junto ao Posto da Polícia Rodoviária Federal no município de Gurupi. Mostrando também o excesso de peso em veículos na região, apresentando os dados mensais e a redução da quantidade de veículos com excesso de peso ao longo da fiscalização.

Os dados mensais da pesagem, foram adquiridos no período de agosto de 2019 a março de 2020, juntamente com os registros fotográficos que estão disponíveis na pasta Estado do Tocantins - Anexo V. Por meio da Unidade Móvel Operacional (UMO) também foram coletados os seguintes dados: Imagem Frontal; Imagem Traseira; Imagem Lateral Direita; Imagem Lateral Esquerda; Comprimento do Veículo; Largura do Veículo; Altura do Veículo; Hora da Pesagem.

Os dados foram cedidos pelo Orientador deste trabalho e Mestre em Engenharia Civil, a partir da fiscalização realizada pelo Departamento Nacional de Infraestrutura de Transportes - DNIT (processo n ${ }^{\circ}$ 50623.001141/2020-42) e em formato gráfico. Os gráficos abordam temas como:

- Total de Veículos por Classe: Pesados, Liberados e Notificados;

- Total de Notificações por Classe de Veículos;

- Total de Veículos: Liberados e Notificados;

- Total de Veículos por DIA: Pesados, Liberados e Notificados;

- $\quad$ Total de Notificações por DIA: PBT, Eixo e CMT;

- $\quad$ Total de Excesso de Peso;

- Total de Excesso de Peso por DIA: PBT, Eixo e CMT.

\section{Resultados e Discussão}

A seguir estão apresentados gráficos onde constam mês a mês a variação de quantitativo dos resultados obtidos ao longo desse período de fiscalização. 
Gráfico 1- Total de Veículos Fiscalizados e Notificados.

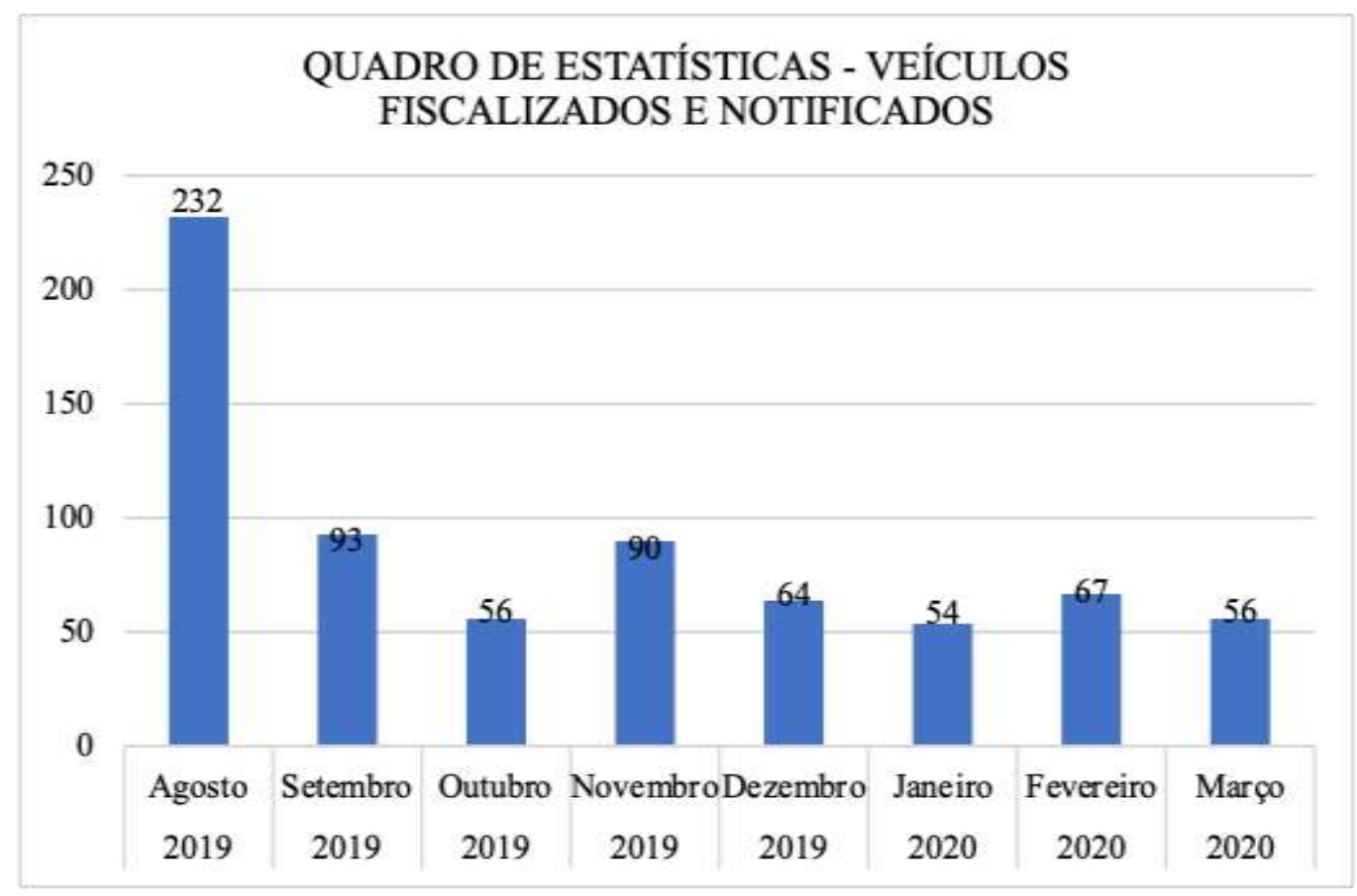

Fonte: Autores (2021).

Gráfico 2-Veículos Fiscalizados - Excesso de Peso PBT.

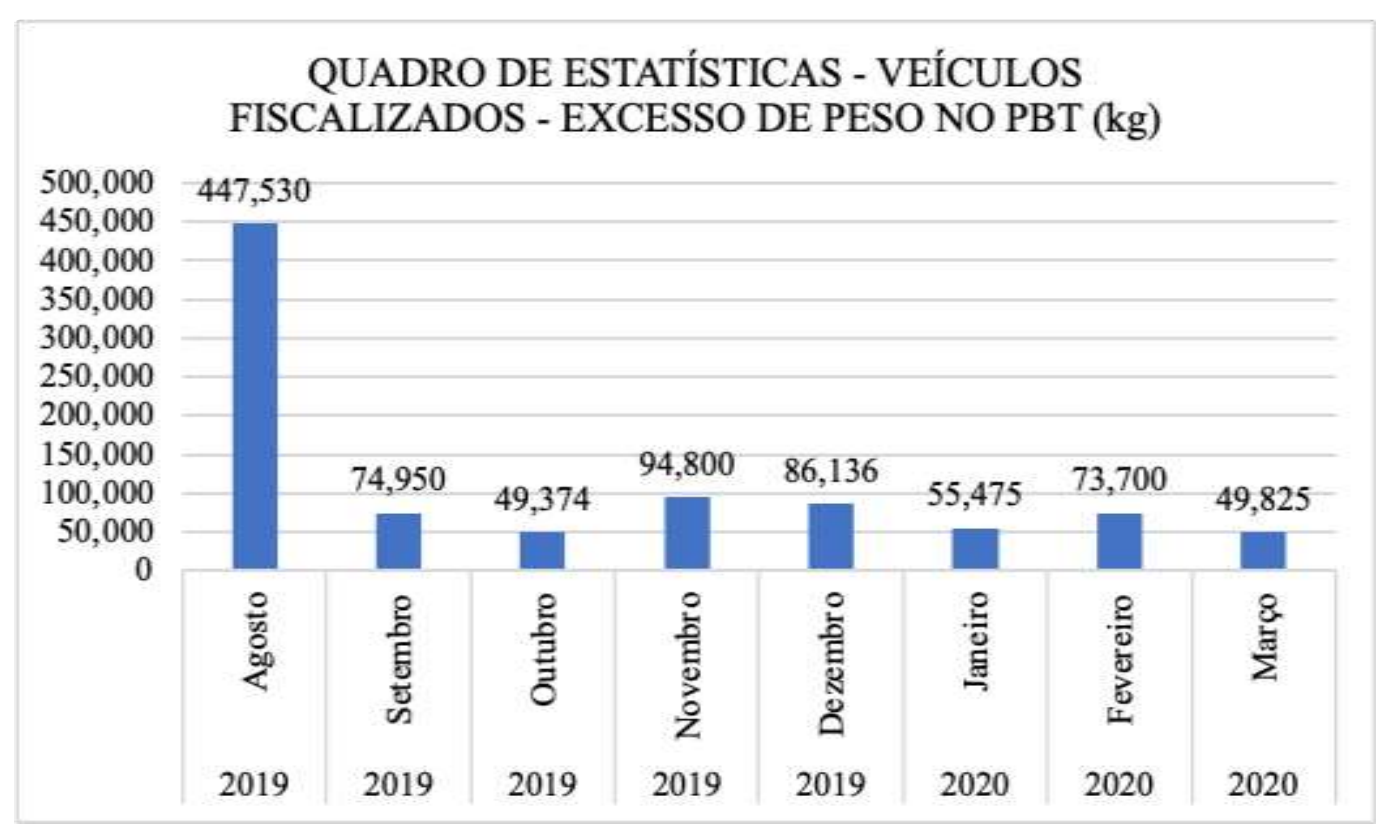

Fonte: Autores (2021). 
Gráfico 3- Veículos Fiscalizados - Excesso de Peso No EIXO.

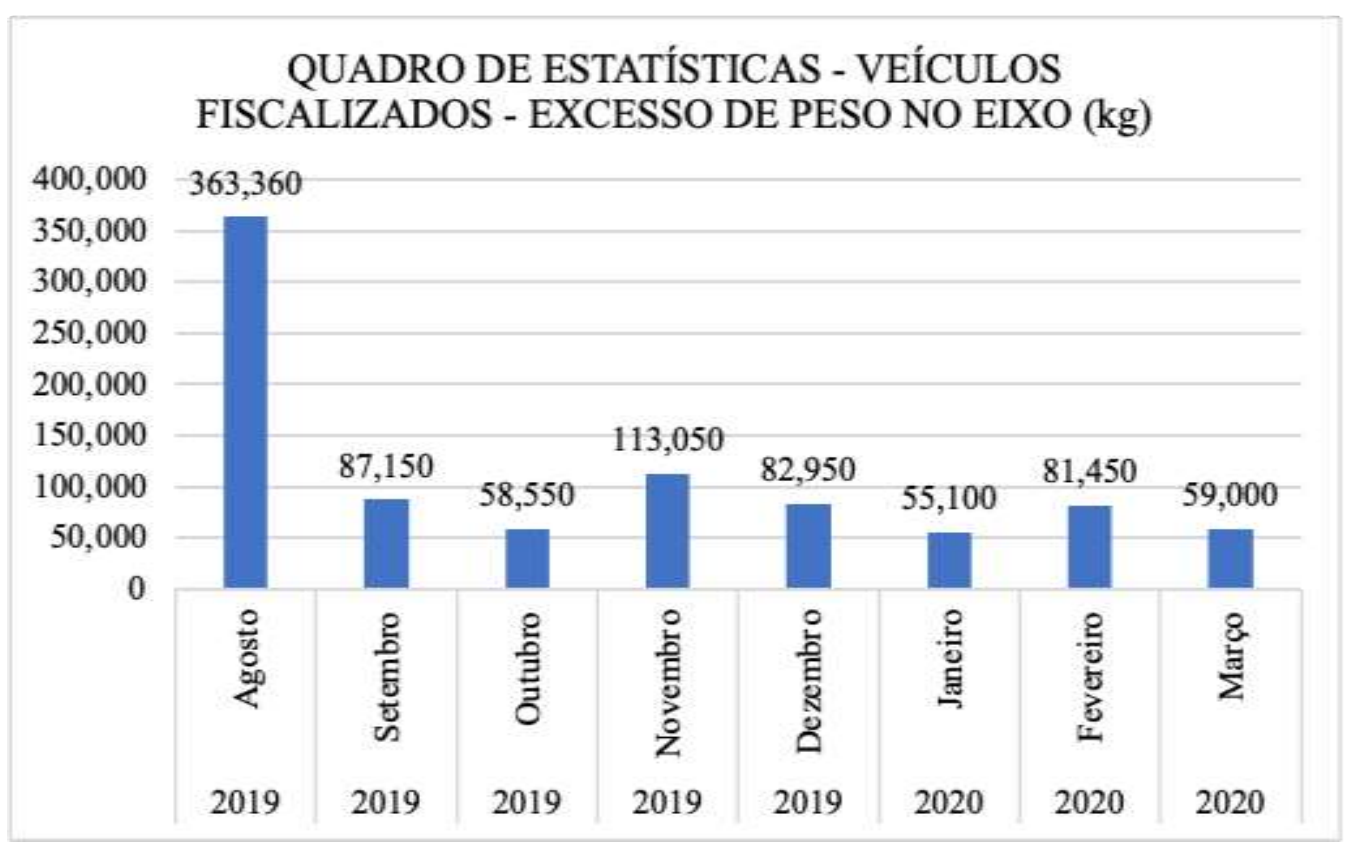

Fonte: Autores (2021).

Conforme verifica-se no Gráfico 1, a ocorrência da fiscalização inibe o tráfego com excesso de peso, o que resulta numa diminuição no número de veículos notificados por mês.

Da mesma forma como se verifica no Gráfico 1 a diminuição de veículos notificados, ocorreu a diminuição do volume do excesso de peso como pode ser observado no Gráfico 2. Observa-se que o mês de agosto, quando iniciou a fiscalização, apresenta um resultado extremamente alto, em relação ao último dado coletado que apresentou redução de mais da metade.

O mesmo ocorre com o excesso de peso no eixo, que no primeiro mês de operação as quantidades foram bem maiores, visto que contou com o efeito surpresa. Entretanto, ao longo dos outros meses a quantidade de excesso de peso notificado diminuiu, parte pela mudança de comportamento do usuário da rodovia, que passou a respeitar os limites estabelecidos na legislação vigente. Parte dessa redução de excesso de peso apurada pela fiscalização pode estar distorcida, uma vez que a UMO opera somente em dias úteis, durante 7 horas por dia, inclusive com intervalo de 1 hora para o almoço. Portanto, parte dessa redução de notificações de infrações identificadas pela fiscalização pode ser simplesmente a mudança de comportamento do transportador, ou seja, trafegar fora do horário comercial, no horário do almoço, buscando trafegar nos horários que não há fiscalização.

Outro aspecto também que pode ter contribuído para redução de notificações é o fato da localização da UMO ser junto ao posto da PRF, o que proporciona a coerção da presença da polícia, por outro lado está localização permite que parte do tráfego seja desviado, como rota de fuga, para dentro da cidade de Gurupi, passando pelo distrito industrial, saindo poucos quilômetros após o posto da PRF, evitando desta forma a fiscalização da UMO.

\section{Conclusão}

Através da análise detalhada de todos os resultados, constatou-se que no período em que a UMO atuou no local, o tráfego de veículos com excesso de peso foi reduzido significativamente, indicando que a fiscalização tem papel fundamental para o controle do excesso de peso e, consequentemente no aumento da vida útil do pavimento.

Diante do exposto, é evidente que a fiscalização deve ser em tempo integral para que seja efetiva, ou seja, durante 
24 horas por dia nos 7 dias da semana. Tornando obrigatória a fiscalização de todos os veículos, diferente do que é realizado atualmente, a qual é feita por amostragem em menos de 5\% dos veículos comerciais que trafegam na rodovia.

Tendo em vista os aspectos mencionados, entende-se que a situação atual do transporte de cargas da rodovia BR 153 em Gurupi é preocupante, já que falta fiscalização e consciência por parte dos motoristas e empresas responsáveis. É imprescindível a realização de ação conjunta de controle e impedimento do tráfego de veículos com elevada capacidade de carga dentro da cidade de Gurupi, para evitar desta forma a utilização das vias urbanas como rota de fuga.

\section{Referências}

Albano, J. F. (2005). Efeitos dos excessos de carga sobre a durabilidade de pavimentos. Tese (Doutorado). http://hdl.handle.net/10183/4498

Andrade, V. R. A., \& Truppel Filho, J. O., (2014). Policiamento e fiscalização do trânsito urbano: uma análise do papel das polícias militares. Revista Ordem Pública, 7(1), 221-237.

Brasil. C. (2012). Câmara dos Deputados. Fiscalização de Excesso de Peso em Rodovias. Texto de Rodrigo César Neiva Borges. Brasília: Consultoria Legislativa.

de Pavimentação, D. M., (2006). Departamento Nacional de Infraestrutura de Transportes. Diretoria de Planejamento e Pesquisa. Coordenação Geral de Estudos e Pesquisa. Instituto de Pesquisas Rodoviárias.

Brasil. Departamento Nacional de Infraestrutura de Transportes. Ministério dos Transportes. Ministério da Infraestrutura. Coordenação de Planejamento. Plano Nacional e Sistema Nacional de Viação. Tabela SNV. Rio de Janeiro, 2020.

Contran, Resolução n ${ }^{\circ}$ 210, de 13/11/2006. Estabelece os limites de peso e dimensões para veículos que transitem por vias terrestres e dá outras providências. Código de Trânsito Brasileiro, Brasília, art. 12, inc. I, da lei no 9.503, 2006.

Contran, Resolução n ${ }^{\circ}$ 211, de 13/11/2006. Requisitos necessários à circulação de Combinações de Veículos de Carga - CVC. Código de Trânsito Brasileiro, Brasília, art. 12, inc. I, da lei $\mathrm{n}^{\circ} 9.503,2006$.

Contran, Resolução ${ }^{\circ}$ 526, de 29/04/2015. Conselho Nacional de Trânsito. Coordenação do Sistema Nacional de Trânsito. Código de Trânsito Brasileiro, Brasília, art. 12, inc. I, da lei $\mathrm{n}^{\circ}$ 9.503, 1997.

Flek, C. M., (2017). Diagnóstico de patologias encontradas na rodovia br-050 entre Araguari e Uberlândia. CONSTRUINDO, 9(3), 48-61.

Fonseca, L. F. S., (2013). Análise das soluções de pavimentação do programa CREMA $2^{\mathrm{a}}$ etapa do Departamento Nacional de Infraestrutura de Transportes. Projeto aplicado (mestrado), UFRJ/COPPE/Programa de Engenharia Civil, 226p.

Fonseca, L.F.S., (2020). Estudo das cargas rodoviárias. Gurupi.

Fontenele, H. B., Zanuncio, C. E. M., \& da Silva Junior, C. A. P., (2011). O excesso de peso nos veículos rodoviários de carga e seu efeito Truck overload and its effects. Teoria e Prática na Engenharia Civil, (18), 95-103.

Klamt, R.A., (2017). A influência da sobrecarga nos pavimentos e a importância da fiscalização de pesagem veicular nas rodovias brasileiras. Revista CIATEC, Passo Fundo, 9(3), 52-61.

Machado, D. M. C., (2013). Avaliação de normas de identificação de defeitos para fins de gerência de pavimentos flexíveis (Doctoral dissertation, Universidade de São Paulo).

Nunes, M. L., (2008). Análise da trajetória da fiscalização do excesso de peso das cargas transportadas nas rodovias do Brasil especialmente no estado de Minas Gerais.

Pessoa, F. H. C., (2012). Avaliações funcional e estrutural de trechos de rodovias no Distrito Federal construídos com diferentes materiais.

Réus, T. F., da Silva Junior, C. A. P., \& Fontenele, H. B., (2014). Análise empírico-mecanista do efeito do excesso de carga veículos comerciais. REECRevista Eletrônica de Engenharia Civil, 9(2).

Padilha, L. T. (2015). Avaliação da Tolerância de Peso Permitida Por Eixo no Dimensionamento de Pavimentos Flexíveis.

Silva, T. O. D., Carvalho, C. A. B. D., Lima, D. C. D., Calijuri, M. L., \& Machado, C. C. (2011). Influência do tráfego de veículos comerciais em rodovias vicinais não pavimentadas: estudo de caso aplicado à VCS 346, Viçosa, MG. Revista Árvore, 35(3), 539-545.

Soares, J. B., \& Motta, L. M., (2001). Considerações sobre a Determinação do Fator de Veículo no Cálculo do Número N. In Congresso de Ensino e Pesquisa e Ensino em Transportes (Vol. 15, No. 2001, pp. 381-389). 